artery; as Kawajiri and colleagues ${ }^{3}$ note, however, the angulation from the left subclavian artery does not work favorably to help the proximal end of the aortic stent graft deploy into the distal aortic arch. If the left brachial artery approach is used, the wire can be prolapsed into the ascending aorta once the thoracic aortic stent graft has been delivered over the body floss wire. This approach, however, does not provide as much control of the proximal graft deployment as does a wire from the right brachial artery.

Kawajiri and colleagues ${ }^{3}$ elected to remove the brachial femoral wire once the thoracic aortic stent-graft was in place and insert a Lunderquist wire (Cook Medical Inc, Bloomington, Ind). The stiffer Lunderquist wire, when the proximal aspect is placed in the ascending aorta, improved the conformability of the aortic stent graft, which facilitated deployment of the proximal aspect of the graft. The angulation of a wire heading out the innominate artery, as opposed to a stiff wire conforming to the aortic arch, could lead to unintentional bird beaking of the stent graft.
In summary, the brachiofemoral wire, or body floss, technique is another useful tool that all interventionalists need to have at their disposal. This technique is useful in a number of different situations, including hybrid arch procedures with problematic elephant trunks and frozen elephant trunks. It requires expert level familiarity with catheter and wires to be performed safely, and surgeons may want to partner with another specialist as part of the hybrid team for these types of cases.

\section{References}

1. Diethrich EB, Ghazoul M, Wheatley GH III, Alpern JB, Rodriguez-Lopez JA Ramaiah VG. Great vessel transposition for antegrade delivery of the TAG endoprosthesis in the proximal aortic arch. J Endovasc Ther. 2005;12:583-7.

2. Greenberg RK, Haddad F, Svensson L, O'Neill S, Walker E, Lyden SP, et al Hybrid approaches to thoracic aortic aneurysms: the role of endovascular elephant trunk completion. Circulation. 2005;112:2619-26.

3. Kawajiri H, Oka K, Yamasaki T, Koh E. Revisiting the brachiofemoral throughand-through wire technique for hybrid arch repair with a problematic elephant trunk. J Thorac Cardiovasc Surg. 2015;150:250-2.

4. Kpodonu J, Rodriguez-Lopez JA, Ramaiah VG, Diethrich EB. Use of the right brachio-femoral wire approach to manage a thoracic aortic aneurysm in an extremely angulated and tortuous aorta with an endoluminal stent graft. Interact Cardiovasc Thorac Surg. 2008;7:269-71

\title{
Multibranched hybrid device for frozen elephant trunk: What does it change?
}

Vito Giovanni Ruggieri, MD, PhD, Marco Vola, MD, PhD, Amedeo Anselmi, MD, PhD, and Jean Philippe Verhoye, MD, PhD, Rennes, France

See related commentary pages $255-7$.

Introduced in 1996, the frozen elephant trunk is a technique that allows the treatment of degenerative and chronic dissecting aneurysms involving the aortic arch and the proximal descending aorta. ${ }^{1}$ During recent years, various hybrid prostheses have been developed. Reported series have shown satisfactory perioperative and midterm results of the frozen elephant trunk. ${ }^{2,3}$ The Thoraflex prosthesis (Vascutek Terumo, Inchinnan, UK) is a new device with selective supra-aortic branches and a sewing collar (Figure 1). We

\footnotetext{
From the Department of Cardiovascular and Thoracic Surgery, Pontchaillou University Hospital, Rennes, France.

Disclosures: Vito Giovanni Ruggieri reports consulting fees from Vascutek Terumo. All other authors have nothing to disclose with regard to commercial support.

Received for publication Feb 6, 2015; accepted for publication March 15, 2015; available ahead of print April 8, 2015.

Address for reprints: Vito Giovanni Ruggieri, MD, PhD, Department of Cardiovascular and Thoracic Surgery, Pontchaillou University Hospital, 2 Rue Henri Le Guilloux, 35000 Rennes, France (E-mail: vito-giovanni.ruggieri@chu-rennes.fr). J Thorac Cardiovasc Surg 2015;150:253-5 $0022-5223 / \$ 36.00$

Copyright (c) 2015 by The American Association for Thoracic Surgery http://dx.doi.org/10.1016/j.jtcvs.2015.03.018
}

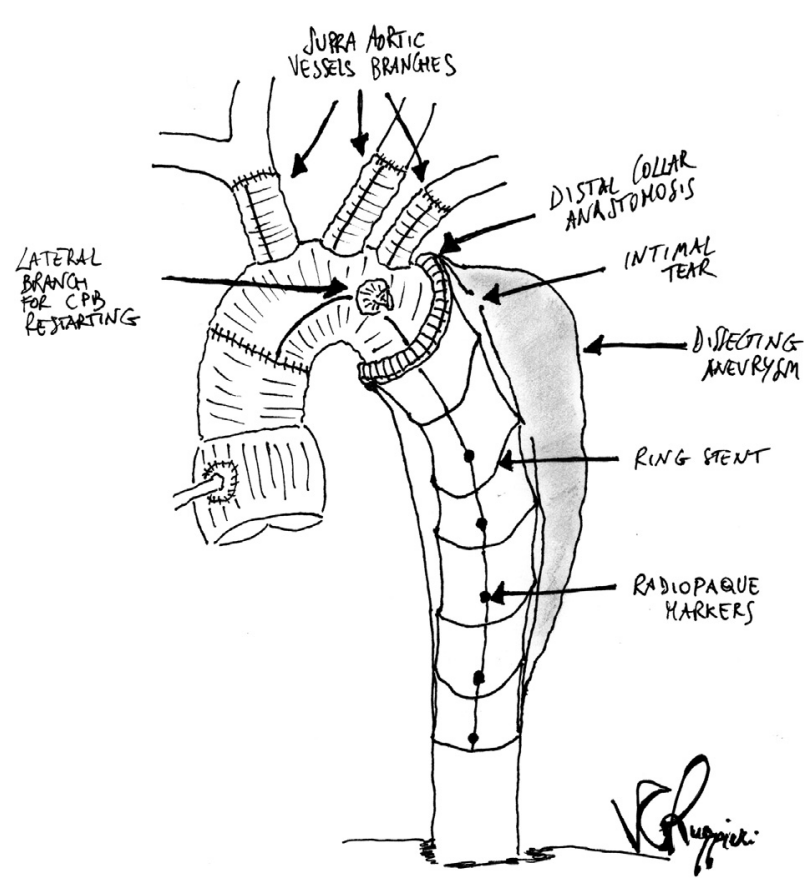

FIGURE 1. Frozen elephant trunk with Thoraflex (Vascutek Terumo, Inchinnan, UK) multibranched hybrid device. 
TABLE 1. Patients and procedural data

\begin{tabular}{|c|c|c|c|c|c|c|c|c|c|c|c|}
\hline Case & $\begin{array}{c}\text { Thoracic } \\
\text { aorta disease }\end{array}$ & $\begin{array}{c}\text { Previous } \\
\text { cardiac } \\
\text { operation }\end{array}$ & $\begin{array}{l}\text { Associated } \\
\text { procedure }\end{array}$ & $\begin{array}{l}\text { Landing zone } \\
\text { diameter (mm) }\end{array}$ & $\begin{array}{c}\text { Thoraflex } \\
\text { device } \\
\text { size }(\mathbf{m m}) \\
\end{array}$ & $\begin{array}{c}\text { Arterial } \\
\text { cannulation }\end{array}$ & $\begin{array}{l}\text { CPB } \\
\text { time } \\
(\mathrm{min}) \\
\end{array}$ & $\begin{array}{c}\text { ACC } \\
\text { time } \\
(\mathrm{min}) \\
\end{array}$ & $\begin{array}{c}\text { CA } \\
\text { time } \\
(\mathbf{m i n}) \\
\end{array}$ & $\begin{array}{c}\text { ACP } \\
\text { time } \\
(\mathrm{min}) \\
\end{array}$ & $\begin{array}{c}\text { SAV } \\
\text { reimplantation } \\
\text { technique } \\
\end{array}$ \\
\hline 1 & Chronic dissection & AAR and AVRp & None & 24 & $26 / 28 / 150$ & AxA & 215 & 129 & 62 & 87 & En bloc \\
\hline 2 & Aneurysm & None & AAR and AVRp & 31 & $30 / 36 / 150$ & AAo and FemA & 211 & 107 & $7^{*}$ & 92 & Separate \\
\hline 3 & Aneurysm & None & AAR and AVR & 29 & $30 / 34 / 150$ & AAo & 203 & 108 & 54 & 77 & Separate \\
\hline 4 & Chronic dissection & AAR and AVRp & None & 28 & $30 / 32 / 150$ & AAo & 197 & 97 & 46 & 88 & Separate \\
\hline 5 & Aneurysm & None & CABG & 24 & $26 / 28 / 100$ & AxA & 206 & 89 & 50 & 81 & Separate \\
\hline 6 & Chronic dissection & None & Bentall & 34 & $32 / 40 / 150$ & AAo & 255 & 187 & 83 & 166 & Separate \\
\hline
\end{tabular}

$C P B$, Cardiopulmonary bypass; $A C C$, aortic crossclamp; $C A$, circulatory arrest; $A C P$, antegrade cerebral perfusion; $S A V$, supra-aortic vessels; $A A R$, ascending aorta replacement; $A V R p$, aortic valve repair; $A x A$, axillary artery; $A A o$, ascending aorta; Fem $A$, femoral artery; $A V R$, aortic valve replacement; $C A B G$, coronary artery bypass grafting. *In this case, visceral perfusion was realized through a femoral artery cannula.

present our initial experience with the Thoraflex device in 6 patients with various chronic aortic pathologies (Table 1).

\section{SURGICAL TECHNIQUE}

The Thoraflex hybrid prosthesis (Figure 2, $A$ and $B$ ) is used for aortic arch and descending aorta replacement during moderate hypodermic circulatory arrest $\left(26^{\circ} \mathrm{C}\right)$ and antegrade selective cerebral perfusion $(10 \mathrm{~mL} / \mathrm{kg} / \mathrm{min})$. The stented portion of the Thoraflex graft can be slightly shaped to conform to the anatomy of the descending thoracic aorta and pushed down over a guidewire (Figure 2, C). The handle is used to stabilize the graft in the correct position, paying attention to the right cranial position of supra-aortic vessel branches. The sheath is retracted back through the splitter to deploy the self-expanding stent. The splitter is then removed, and a sewing collar is freed at the junction between the stented and unstented segments. The guidewire is pulled back and the distal stented part completely opened, releasing the red clip on the top of the delivery system. Finally, the delivery system is removed from the hybrid graft. The distal aortic anastomosis at the aortic isthmus is performed first, thanks to the sewing collar, with a 4-0 running Prolene suture (Ethicon, Inc, Somerville, NJ). Once this anastomosis has been completed, the cardiopulmonary bypass arterial line is connected to the side branch of the graft for antegrade distal organ perfusion and rewarming. The proximal aortic anastomosis is then performed with a 4-0 running Prolene suture between the unstented graft and the prosthesis previously sutured, to replace the ascending aorta. The supra-aortic vessel anastomoses are performed after aortic declamping and during rewarming, starting from the left subclavian artery with selective use of the 3 specific branches of the graft. Subsequently, the patient is weaned from cardiopulmonary bypass. A representative postoperative contrast computed tomographic result (case 4) is shown in Figure 2, $D$.
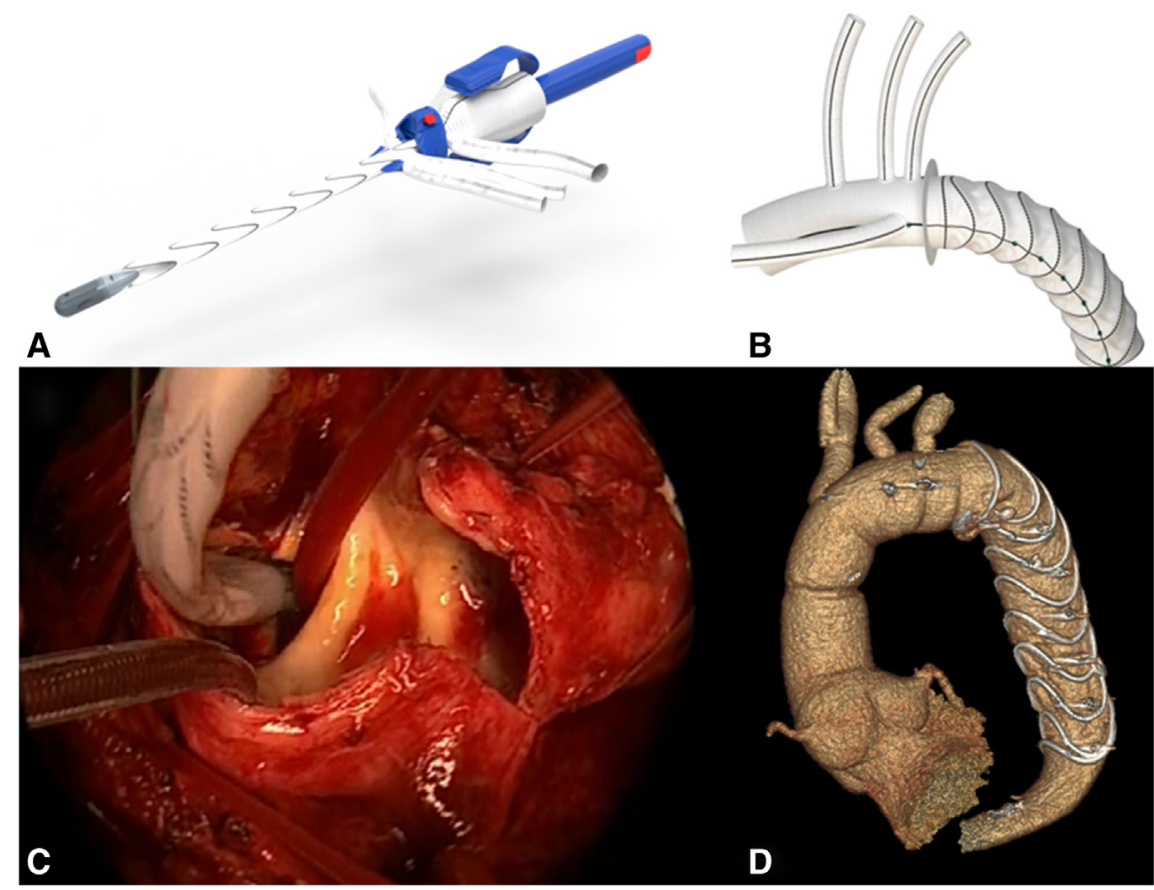

FIGURE 2. A, Thoraflex hybrid graft before implantation. B, Thoraflex hybrid graft after deployment and delivery system removal. C, Insertion of preshaped stented segment into the descending aorta. D, Postoperative computed tomographic result in case 4 . 


\section{DISCUSSION}

Hybrid prostheses enable completion of aortic surgical repair in a single stage, thus avoiding the cumulative mortality and interval mortality associated with 2-stage approaches. A systematic review of 17 studies identified pooled mortality and stroke rate in 2-stage procedures of $8.3 \%$ and $4.9 \%$, respectively. ${ }^{4}$ Cardiopulmonary bypass time, myocardial ischemia time, and circulatory arrest time were strongly correlated with mortality.

The multibranched Thoraflex stent-graft offers several new technical innovations relative to other designs. ${ }^{5}$ First, it is a short and handy device with an easy deployment system. Different sizes of the stented and unstented segments are provided for a better fit with aortic anatomy. Thanks to the malleable shaft, the stented part can be shaped to conform to the isthmus and descending aorta anatomy. This makes the device less traumatic on the descending aortic wall and easier to introduce into the aorta. The sewing collar between the Dacron polyester fabric tube and the stented segment ensures easier and safer anastomosis of the prosthesis to the aortic isthmus, reducing the hemodynamic traction on the anastomosis itself and allowing further hemostatic stitches, when necessary, even at the end of the procedure. The grafts' branches allow separate reimplantation of the supra-aortic vessels, enabling shorter ischemic visceral and myocardial durations, although en bloc reimplantation remains possible. Separate reimplantation also allows better individual hemostatic control of supra-aortic vessel anastomoses, including the isthmus anastomosis. This technique for arch vessels may be relevant when their origins are distant from each other or dissected and in patients for whom a radical aortic resection may be needed, such as those with connective diseases or severe calcifications or clots at the proximal portions of the vessels. In some cases, the left subclavian anastomosis may be difficult to perform because of the closed position of the branch to the corresponding vessel and may need to be realized before the pump is restarted. This can minimally increase the visceral ischemic time. Finally, the radiopaque markers in the stented portion of the Thoraflex prosthesis further simplify endovascular completion when necessary.

After this initial experience, we consider the Thoraflex hybrid prosthesis to be a versatile device representing a suitable alternative for management of complex chronic aortic pathologies involving the arch and the proximal descending aorta.

The authors are grateful to Dr Agnino and to the members of CardioMiss Association for their invaluable help and outstanding support in the development of this aortic surgery program.

\section{References}

1. Kato M, Ohnishi K, Kaneko M, Ueda T, Kishi D, Mizushima T, et al. New graftimplanting method for thoracic aortic aneurysm or dissection with a stented graft. Circulation. 1996;94(9 Suppl):II188-93.

2. Ius F, Fleissner F, Pichlmaier M, Karck M, Martens A, Haverich A, et al Total aortic arch replacement with the frozen elephant trunk technique: 10year follow-up single centre experience. Eur J Cardiothorac Surg. 2013;44: 949-57.

3. Verhoye JP, Anselmi A, Kaladji A, Flécher E, Lucas A, Heautot JF, et al. Mid-term results of elective repair of extensive thoracic aortic pathology by the Evita Open Plus hybrid endoprosthesis only. Eur J Cardiothorac Surg. 2014;45:812-7.

4. Tian DH, Wan B, Di Eusanio M, Black D, Yan TD. A systematic review and metaanalysis on the safety and efficacy of the frozen elephant trunk technique in aortic arch surgery. Ann Cardiothorac Surg. 2013;2:581-91.

5. Yan TD, Field M, Tian DH, Bashir M, Oo A. Aortic root and total arch replacement with frozen elephant trunk procedure, using a Thoraflex Hybrid Graft. Ann Cardiothorac Surg. 2013;2:667-8.

\title{
EDITORIAL COMMENTARY
}

\section{Four-branched graft with stent hybrid prosthesis for single-stage treatment of chronic aortic arch pathology}

\author{
Prashanth Vallabhajosyula, MD, MS, and Wilson Y. Szeto, MD
}

\footnotetext{
From the Division of Cardiovascular Surgery, Penn Presbyterian Medical Center, Philadelphia, Pa.

Disclosures: Authors have nothing to disclose with regard to commercial support.

Received for publication April 7, 2015; accepted for publication April 7, 2015; available ahead of print May 13, 2015.

Address for reprints: Wilson Y. Szeto, MD, Division of Cardiovascular Surgery, Penn Presbyterian Medical Center, Heart and Vascular Pavilion Suite 2A, Philadelphia, PA 19104 (E-mail: Wilson.szeto@uphs.upenn.edu).

J Thorac Cardiovasc Surg 2015;150:255-7

$0022-5223 / \$ 36.00$

Copyright (c) 2015 by The American Association for Thoracic Surgery

http://dx.doi.org/10.1016/j.jtcvs.2015.04.023
}

See related article on pages 253-5.

Treating chronic aortic arch pathologies such as dissection and aneurysm can be quite complex because typically it involves addressing the aortic arch and the proximal descending thoracic aorta (DTA). Single-stage operation for this pathology requires a thoracosternotomy incision to replace 